\title{
Unexpected Irregular Monoterpene "Yomogi Alcohol" in the Volatiles of the Lathyrus L. species (Leguminosae) of Cyprus
}

\author{
Kaan Polatoğlu ${ }^{1 *}$, Seniha Arsal' ${ }^{2}$, Betül Demirci ${ }^{3}$ and Kemal Hüsnü Can Başer ${ }^{3,4}$ \\ ${ }^{1}$ Istanbul Kemerburgaz University, Faculty of Pharmacy, Department of Analytical Chemistry, 34217 Istanbul, TURKEY \\ ${ }^{2}$ Near East University, Faculty of Pharmacy, Department of Analytical Chemistry, 10 Mersin/Nicosia, TURKEY \\ ${ }^{3}$ Anadolu University, Faculty of Pharmacy, Department of Pharmacognosy, 26470 Eskişehir, TURKEY \\ ${ }^{4}$ King Saud University, College of Science, Department of Botany and Microbiology, Riyadh, SAUDI ARABIA
}

\begin{abstract}
Lathyrus species including L. ochrus and $L$. sativus are known for their food, feed and horticultural uses. Despite their widespread uses and cultivation, there is limited information on their chemistry. Previously, only the essential oil composition of $L$. rotundifolius, $L$. vernus and volatiles of $L$. odoratus have been reported. In the present research, volatiles of seven Lathyrus $L$. species, namely, $L$. aphaca, $L$. ochrus, L. cicera, L. sativus, L. gorgonei, $L$. saxatilis and $L$. blepharicarpos var. cyprius were analyzed by SPME GC-MS for the first time. Plant materials were collected from five different locations in Cyprus (February-March 2012). The main components of $L$. aphaca volatiles from four locations were yomogi alcohol $26.1-16.5 \%$, camphor $21.6-10.1 \%$, tetradecane $14.3-0 \%$; $L$. cicera from five locations were yomogi alcohol 20.3-3.0\%, camphor 18.7-2.0\%; L. gorgonei from two locations were yomogi alcohol 24.5$13.1 \%$, camphor $17.1-9.0 \%$ and $L$. sativus was yomogi alcohol $11.4 \%$, camphor $9.0 \%$. Yomogi alcohol was not present as the major compound in $L$. ochrus (2-methyl butanoic acid $7.2 \%$ ), $L$. saxatilis (hexanal $7.7 \%$ ) and $L$. blepharicarpos var. cyprius $((Z)-3$-hexenal $8.6 \%)$ volatiles. The volatiles of the Lathyrus species were also compared with each other quantitative and qualitatively using AHC analysis to find out differences among the species. The irregular monoterpene yomogi alcohol is reported from the Lathyrus and the Leguminosae family for the first time. The existence of yomogi alcohol in Lathyrus volatiles points out that the irregular monoterpenes are not restricted solely to Asteraceae family.
\end{abstract}

Key words: Leguminosae, Lathyrus, volatiles, yomogi alcohol, SPME, chemotypes

\section{Introduction}

Lathyrus L. species of Fabaceae are well known with their food, livestock feed and horticultural uses as well as for the notorious "Lathyrism" illness caused by the over consumption of the Lathyrus species that contains the special amino acid of this genus "oxally di amino propionic acid" ${ }^{1)}$. This genus is represented with nine species in Cyprus. Lathyrus ochrus (L.) DC. (Luvana) and L. sativus L. are cultivated for edible and livestock feed uses ${ }^{2}$. Previously there are only a couple of investigations on the volatiles or essential oil composition of the Lathyrus species. These include essential oil composition of $L$. rotundifolius Willd. (Germacrene D 50.4\%; germacrene B 18.7\%; $\gamma$-elemene $9.5 \%$ ), L. vernus L. (Flower and stem oils respectively palmitic acid 34.2 - 35.3\%, 1-octen-3-ol 49.8\%),
L. ochrus L. (Aerial parts oil phytol 49.39\% and hexadecanoic acid $20.64 \%$ ) and volatile composition of three different cultivars of $L$. odoratus $((E)$ - $\beta$-ocimene $46.5-22.9 \%$, linalool 26.2-16.6\%, nerol 10.1-3.3\%, $(Z)$ - $\beta$-ocimene $7.3-$ $2.3 \%$, geraniol $6.5-4.5 \%)^{3-6)}$. Non-volatile secondary metabolites reported from Lathyrus species include new flavonoids, flavonols, chalcones, pterocarpans, saponins as well as known sterols ${ }^{7-14}$. Additionally new primary metabolites were also reported from Lathyrus species that include amino acids $\alpha$-N-oxalyl-L- $\alpha, \beta$-diaminopropionic acid ( $\alpha$-ODAP), $\beta$-N-oxalyl-L- $\alpha, \beta$-diaminopropionic acid $\left(\beta\right.$-ODAP) and carbohydrate L-bornesitol ${ }^{15,16)}$

Previously, very little information related to the volatile composition of the Lathyrus species existed in the literature and no report was present on L. ochrus and $L$.

\footnotetext{
*Correspondence to: Dr. Kaan POLATOĞLU, İstanbul Kemerburgaz University, Faculty of Pharmacy, Department of Analytical Chemistry, 34217 İstanbul, TURKEY

E-mail: kaanpolatoglu@gmail.com / kaan.polatoglu@ kemerburgaz.edu.tr

Accepted December 16, 2015 (received for review July 10, 2015)

Journal of Oleo Science ISSN 1345-8957 print / ISSN 1347-3352 online

http://www.jstage.jst.go.jp/browse/jos/ http://mc.manusriptcentral.com/jjocs
} 
sativus cultivated as food products. Prior to this study we have investigated essential oil composition of L. ochrus which we have reported to have the main components of the oil as diterpenes and alkanes. However to our surprise we have not identified any monoterpene and sesquiterpene type compounds ${ }^{5}$. Previous reports indicated that essential oils of other Lathyrus species contained monoterpenes and sesquiterpenes. In our present study, we attempted to identify the volatile composition of the Lathyrus species of Cyprus as a part of our phytochemical composition and biological activity screening of this genus. Here, we report on the volatile composition of seven species including $L$. aphaca L., L. ochrus (L.) DC., L. cicera L., L. sativus L., L. gorgonei Parl., L. saxatilis (Vent.) Vis. and L. blepharicarpos Boiss. var. cyprius Meikle. Volatiles of these species were obtained by solid phase micro extraction method and analysed by gas chromatography - mass spectrometry. Comparison of the volatile composition of the investigated Lathyrus species was performed using agglomerative hierarchical cluster analysis in order to provide similarity/dissimilarity of the volatile secondary metabolite profiles of the mentioned species. To the best of our knowledge, their chemical compositions are reported for the first time.

\section{Materials and Methods}

\subsection{Plant Materials}

Plant materials were collected during the flowering period between 11 February - 13 April 2012 from five dif- ferent locations (Yeniceköy, Kalavaç, Kaleburnu, Haspolat, Güzelyurt) in Cyprus. Voucher specimens have been deposited at the Herbarium in the Near East University, Cyprus. Plant materials were identified by Dr. Kaan Polatoglu and Dr. Salih Gucel. The collection dates and locations of the plant materials used in the research and their voucher specimen numbers were given in Table 1.

\subsection{Isolation of the Volatiles}

Aerial parts of the fresh plant material $(0.5 \mathrm{~g})$ were placed in a $10 \mathrm{~mL}$ vial and sealed with parafilm. Headspace solid phase micro extraction (Headspace SPME) was used for the isolation of the volatiles. A manual SPME injector (Supelco, Ballafonte, PA, USA) that have a fibre coated with a layer of polydimethylsiloxane/divinylbenzene $(65 \mu \mathrm{m}$ - PDMS/DVB-blue) was used for the adsorption of the volatiles. Prior to the analysis of adsorbed volatiles on the fiber a blank run was initiated with the fiber to make sure it does not contain any contamination. After the blank run the fiber was inserted into the vial through the parafilm and exposed to the plant volatiles for $15 \mathrm{~min}$ at $50^{\circ} \mathrm{C}$. The SPME injector than inserted immediately to the injection port manually for desorption of the plant volatiles for GC/ MS analysis.

\subsection{Analysis of the Volatiles}

The volatiles were analyzed by GC-MS using a Hewlett Packard GCD system. An HP-Innowax FSC column (60 m × $0.25 \mathrm{~mm}, 0.25 \mu \mathrm{m}$ film thickness) and helium as carrier gas $(0.8 \mathrm{~mL} / \mathrm{min})$. The oven temperature was programmed to $60^{\circ} \mathrm{C}$ for $10 \mathrm{~min}$ and raised to $220^{\circ} \mathrm{C}$ at a rate of $4^{\circ} \mathrm{C} / \mathrm{min}$.

Table 1 Collection locations and voucher specimen numbers of the plant materials used in the research.

\begin{tabular}{llccc}
\hline \multicolumn{1}{c}{ Plant Species } & \multicolumn{1}{c}{ Collection Location } & Collection Date & Altitude & Herbarium No. \\
\hline Lathyrus aphaca & Yeniceköy & 11.02 .2012 & $79 \mathrm{~m}$ & 6795 \\
& Kalavaç & 19.02 .2012 & $179 \mathrm{~m}$ & 6798 \\
& Karpaz - Kaleburnu Köyü Location I & 17.03 .2012 & $24 \mathrm{~m}$ & 6810 \\
& Karpaz - Kaleburnu Köyü Location II & 17.03 .2012 & $81 \mathrm{~m}$ & 6814 \\
Lathyrus blepharicarpus var. cyprius & Karpaz - Kaleburnu Köyü Location I & 09.03 .2012 & $24 \mathrm{~m}$ & 6808 \\
Lathyrus cicera & Haspolat - Location I & 25.02 .2012 & $267 \mathrm{~m}$ & 6800 \\
& Haspolat - Location II & 04.03 .2012 & $267 \mathrm{~m}$ & 6802 \\
& Kalavaç & 04.03 .2012 & $179 \mathrm{~m}$ & 6804 \\
& Karpaz - Kaleburnu Köyü Location I & 09.03 .2012 & $24 \mathrm{~m}$ & 6807 \\
Kathyrus gorgonei & Karpaz - Kaleburnu Köyü Location II & 17.03 .2012 & $81 \mathrm{~m}$ & 6811 \\
& Haspolat - Location I & 25.02 .2012 & $267 \mathrm{~m}$ & 6799 \\
& Karpaz - Kaleburnu Köyü Location I & 09.03 .2012 & $24 \mathrm{~m}$ & 6806 \\
Lathyrus ochrus & Karpaz - Kaleburnu Köyü Location I & 17.03 .2012 & $24 \mathrm{~m}$ & 6809 \\
Lathyrus sativus & Güzelyurt & 18.03 .2012 & - & 6772 \\
Lathyrus saxatalis & Karpaz - Kaleburnu Köyü Location II & 13.04 .2012 & $81 \mathrm{~m}$ & 6817 \\
\hline
\end{tabular}


The temperature kept constant at $220^{\circ} \mathrm{C}$ for $10 \mathrm{~min}$ and then raised to $240^{\circ} \mathrm{C}$ at a rate of $1^{\circ} \mathrm{C} / \mathrm{min}$. The injector temperature was set at $250^{\circ} \mathrm{C}$. Splitless injection mode was employed. Mass spectra were recorded at $70 \mathrm{eV}$ with the mass range $\mathrm{m} / \mathrm{z} 35$ to 450 . The relative percentage of the components of the volatiles were calculated from the integration of the peaks obtained from GC-MS analysis. The results of the analysis are given in Table 2.

\subsection{Identification of the Components}

Identification of the essential oil and volatile components was carried out by comparison of their relative retention times with those of authentic samples or by comparison of their relative retention index (RRI) to series of $n$-alkanes. Computer matching against commercial(Wiley GC/MS Library, MassFinder 3 Library $)^{17,18)}$, and in-house "Başer Library of Essential Oil Constituents" built up by genuine compounds and components of known oils, as well as MS literature data ${ }^{19)}$ was used for the identification.

\subsection{Agglomerative Hierarchical Cluster Analysis}

Volatile composition data of $L$. odoratus ${ }^{6)}$ reported in the literature and the present work was used in the agglomerative hierarchical cluster (AHC) analysis. The data set was prepared based on the qualitative and quantitative properties of the volatiles reported in the literature and from the Headspace SPME GC/MS analysis performed in this research. AHC analysis was performed using XLSTAT - 2014.5.01 program trial version (Addinsoft, New York-U. S.A.). AHC analysis was done using Pearson's dissimilarity method and unweighed pair-group average as aggregation criterion. Dendrogram was obtained showing dissimilarity of the analyzed oils within the range $0-1$. The dendrogram obtained from the AHC analysis was given in Fig. 1.

\section{Results and Discussion}

Seven Lathyrus species of Cyprus obtained from six different locations were investigated for their volatile composition by SPME/GC-MS. The identified portion of the investigated Lathyrus volatiles ranged between 84.4 - 38.3\% (mean $67.2 \%$ for 16 analysis). The main reason for the low percentage of identified parts of the volatiles is due to the unknown main component that occurs nearly in all of the Lathyrus volatiles except for the L. gorgonei sample (6809). The relative percentage of this unidentified compound ranged between $14.8-2.3 \%$.

Previously, essential oil composition of $L$. rotundifolius, $L$. vernus and the volatile composition of $L$. odoratus cultivars were investigated. The reported essential oils were predominated either by sesquiterpenes or by higher alkanes and the volatiles of $L$. odoratus cultivars contained acyclic monoterpenes ${ }^{3,4,6)}$. In our analysis we expectected to observe a similar volatile profile as explained by these reports. However high composition of irregular monoterpene yomogi alcohol and cyclic monoterpene camphor was present in most of the volatiles. Volatile composition of Lathyrus aphaca from four different locations produced three different groups that were separated from each other at 0.28 dissimilarity level in AHC analysis. According to the volatile analysis of $L$. aphaca samples from Karpaz I location (6810 - $24 \mathrm{~m}$ ) and Kalavaç location (6798 - 179 m) were clustered in one group. The plant samples (6810, $6798)$ in this group contain yomogi alcohol $(26.1 \%$ and $16.5 \%)$, camphor (21.6\% and $12.4 \%)$, 2-butoxy ethanol $(6.0 \%$ and $5.5 \%),(Z)-3$-hexenal (8.6\% and absent) and dihydromyrcenol (absent and 5.1\%) respectively. These samples were clustered in a group that is described with a dissimilarity level smaller than 0.1 where dissimilarity ranged $0-1$. The second and the third groups were the samples from Karpaz II location $(6814-81 \mathrm{~m})$ and from Yeniceköy location $(6795-79 \mathrm{~m})$ separated from each other at 0.28 dissimilarity level. These samples contain tetradecane (14.3\% and $4.0 \%)$, camphor (10.1\% and absent), hexanal (absent and 7.7\%), ( $Z$ )-3-hexenal (absent and $7.2 \%)$ and dihydromyrcenol (absent and $6.7 \%$ ) for the samples 6795 and 6814. Volatile composition of L. cicera samples from Haspolat location (6800, 25.Feb.12 - 267 m and 6802, 04.Mar.2012 - $267 \mathrm{~m}$ ), Kalavaç location (6804 -179 m), Karpaz I location (6807 - 24 m) and Karpaz II location $(6811-81 \mathrm{~m})$ were clustered in three different groups which were separated from each other at a minimum 0.31 dissimilarity level in AHC analysis. The first group contains the samples from Karpaz I(6807), Karpaz II (6811) and Haspolat (6802) locations. The volatiles of this group contained yomogi alcohol $(15.4 \%, 11.4 \%, 20.3 \%)$, camphor $(11.3 \%, 6.5 \%, 18.7 \%)$, 2-butoxy ethanol (5.8\%, $1.4 \%, 10.7 \%)$, 1-pentanol $(0.7 \%, 7.6 \%$, absent $),(Z)-3-$ hexenal $(2.8 \%, 8.5 \%$, absent) and hexanal $(2.3 \%, 10.1 \%$, absent) for the samples 6807, 6811 and 6802 respectively. The samples of this group are separated from each other with the maximum of 0.13 dissimilarity level. The $L$. cicera samples from the other two locations Kalavaç (6804) and Haspolat (6800) are separated from each other and from the rest of the other samples with a minimum of 0.31 dissimilarity level. Volatiles of the second and third group contains carvone (16.5\%, absent), p-cymene $(9.8 \%$, absent), yomogi alcohol (6.7\%, 3.0\%), ( $Z$ )-3-hexenal $(4.0 \%, 4.2 \%)$ and tetradecane (absent, $3.0 \%)$ for the samples 6804 and 6800 respectively. Three L. gorgonei samples were collected from two different locations including Haspolat (6799 - 267m) and Karpaz I (6806, 09.Mar.12 $24 \mathrm{~m} ; 6809$, 17.Mar.12 - 24m). All of the L. gorgonei samples were clustered in the same group with 0.13 highest dissimilarity level. Volatiles of the L. gorgonei samples contain yomogi alcohol (13.1\%, 19.1\%, 24.5\%), camphor $(9.0 \%, 14.0 \%, 17.1 \%),(Z)$-3-hexenal $(7.7 \%$, 


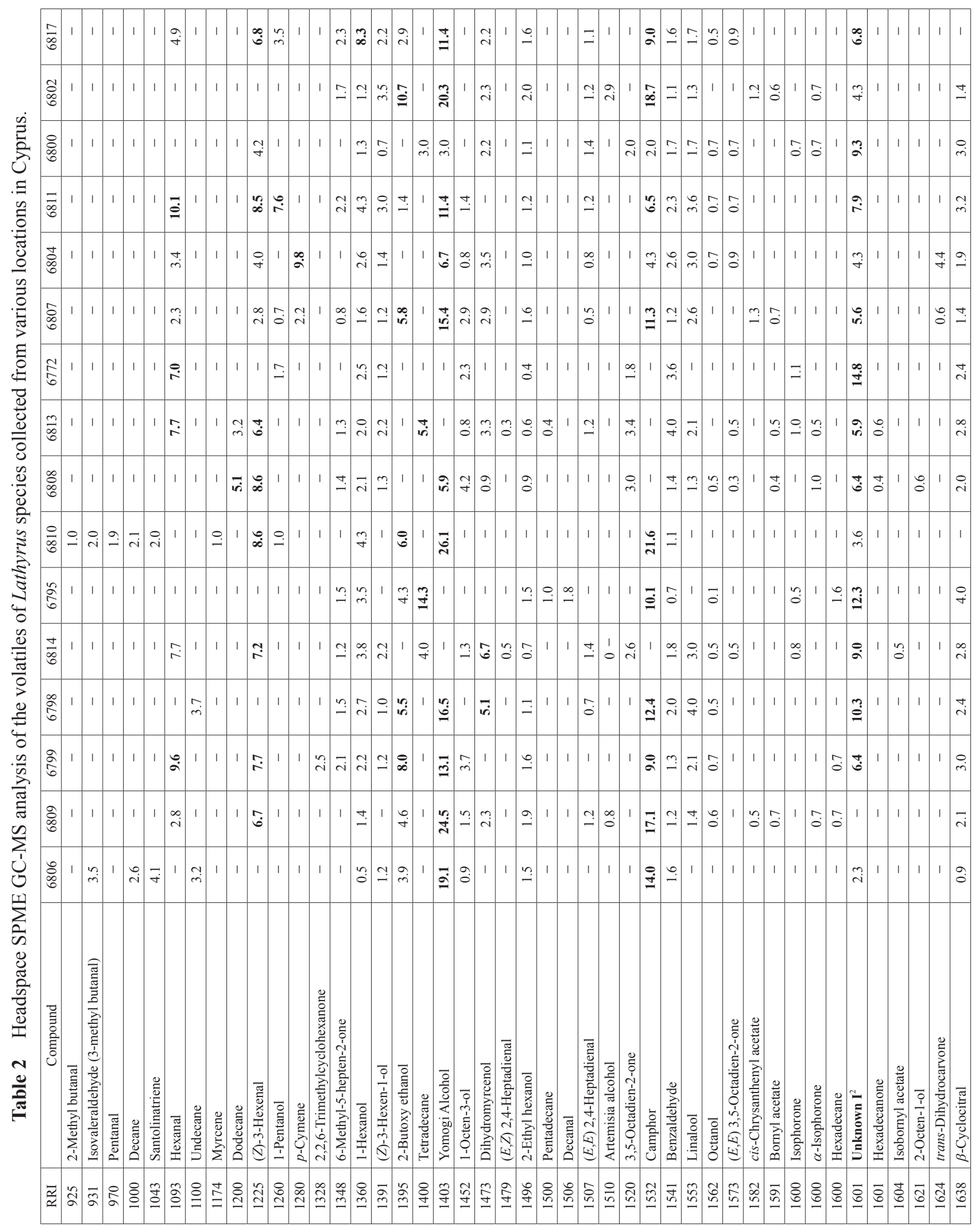




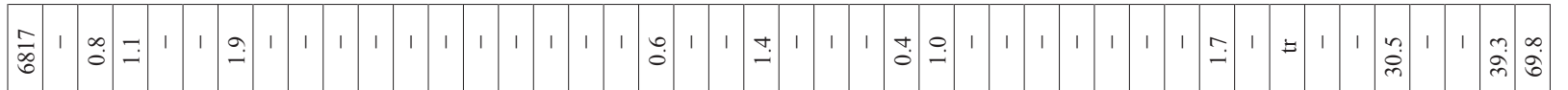

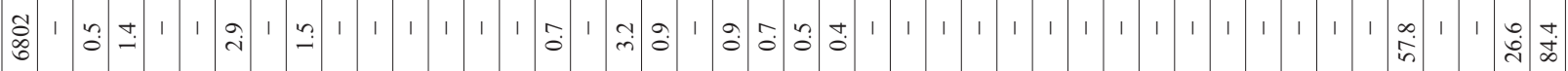

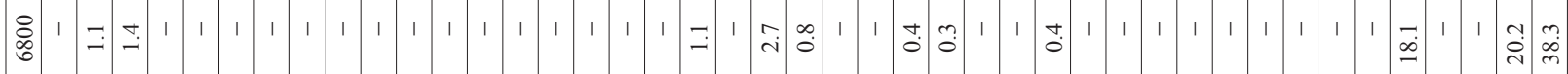

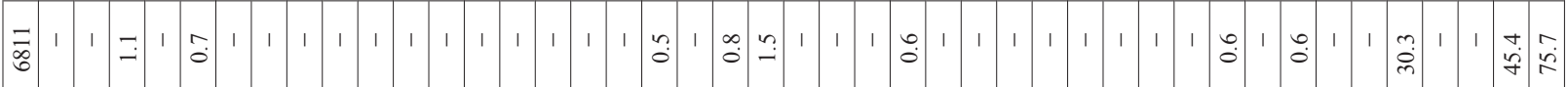

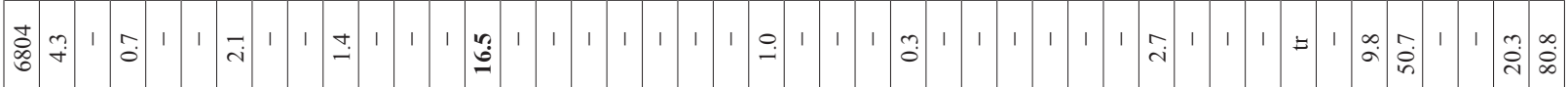

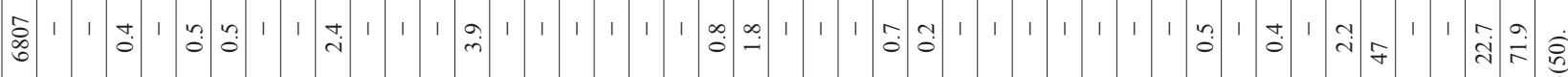

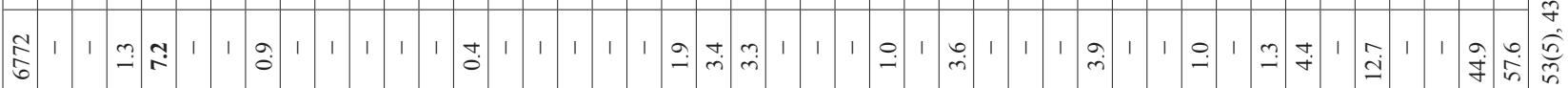

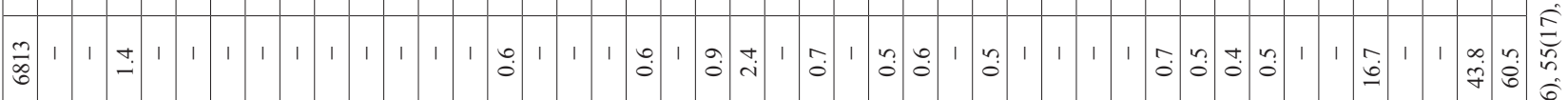

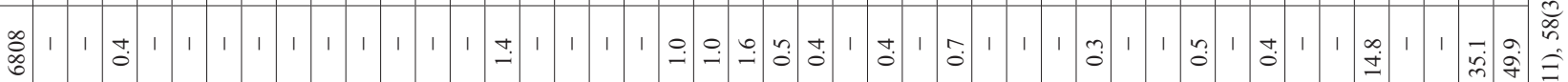

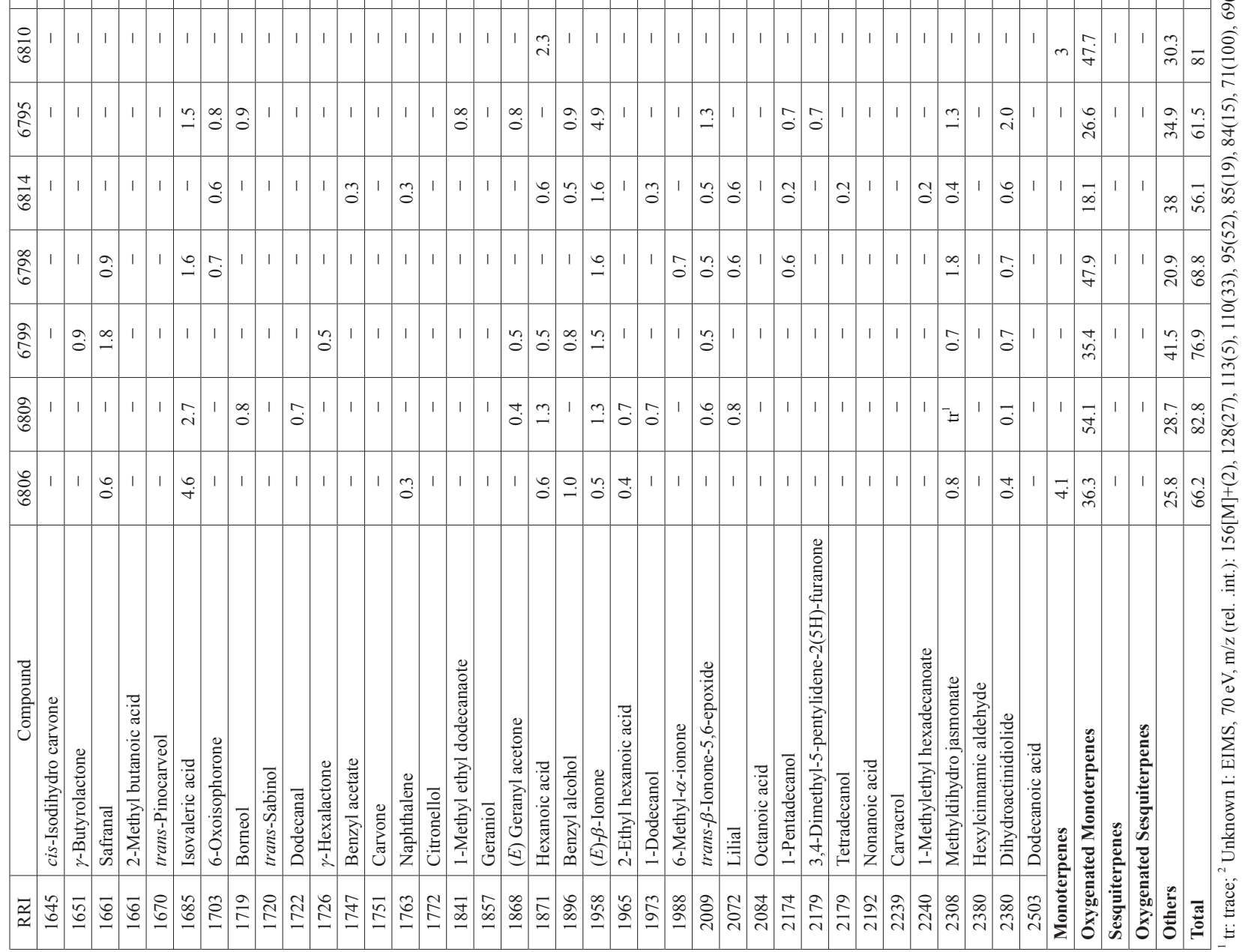




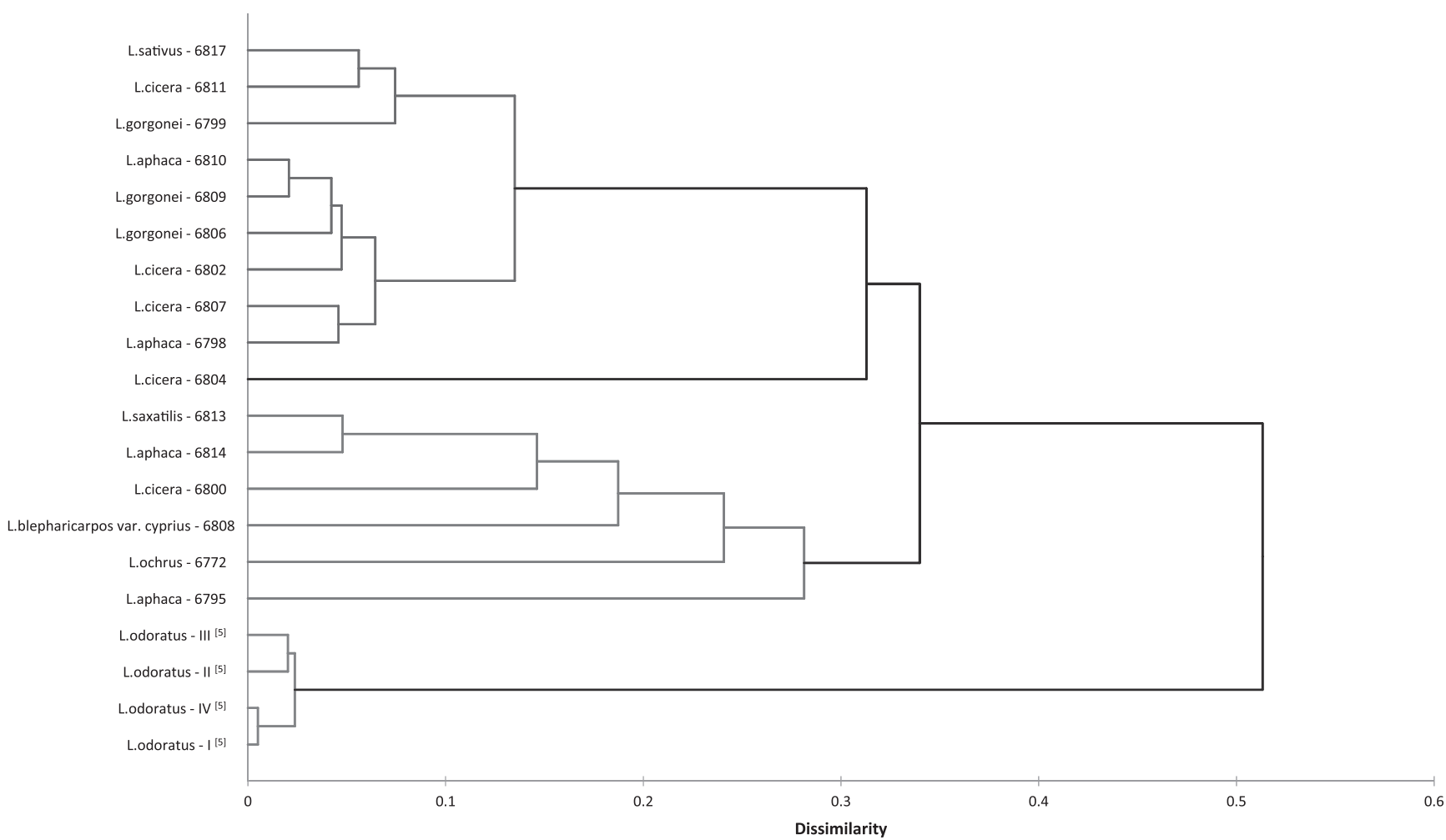

Fig. 1 Dendrogram obtained from the "Agglomerative Hierarchical Cluster" (AHC) analysis of Lathyrus sp. volatiles of Cyprus and the previous literature data.

absent, $6.7 \%$ ) and hexenal (9.6\%, absent, $2.8 \%)$ for the samples 6799,6806 and 6809 respectively. Volatile composition of L. ochrus (6772) were hexenal 7.0\% 2-methyl butanoic acid $7.2 \%$, dodecanoic acid $4.4 \%$, nonanoic acid $3.9 \%$, octanoic acid $3.6 \%$ and benzaldehyde $3.6 \%$. The volatile of $L$. ochrus separated from the rest of the samples with 0.24 minimum dissimilarity. The $L$. sativus volatile composition contains yomogi alcohol $11.4 \%$, camphor $9.0 \%, 1$-hexanol $8.3 \%$ and $(Z)$-3-hexenal $6.8 \%$ as the main components. This plant produced a cluster together with $L$. cicera sample (6811) at 0.06 dissimilarity level. Both plant samples contain the same substances with similar amounts. The volatile composition of $L$. saxatilis contain hexenal $7.7 \%,(Z)$-3-hexenal $6.4 \%$ and tetradecane $5.4 \%$ compounds as the main components. L. saxatilis (6813) clustered together with L. aphaca sample (6814) which contains the similar compounds with similar amounts. The endemic L. blepharicarpos var. cyprius (6808) contains (Z)-3-hexenal 8.6\%, yomogi alcohol 5.9\% and dodecane $5.1 \%$ main components in its volatiles. The volatiles of this plant are separated from the closest group with 0.18 dissimilarity. The agglomerative hierarchical cluster analysis clearly revealed the similarity and dissimilarity of the samples of the same species from different locations and collection dates as well as with the samples of different species. According to the results there are three different potential chemotypes of $L$. aphaca in the analyzed samples. These potential chemotypes contain yomogi alcohol/camphor $(6810,6798)$; hexenal/ $(Z)$-3-hexenal (6814) and tetradecane/camphor (6795) main components. The similar situation is also present for $L$. cicera that produced three different potential chemotypes. The potential chemotypes for L. cicera are yomogi alcohol/camphor (6811, 6802, 6807) ; carvone/p-cymene/yomogi alcohol (6804) and ( $Z$ )-3-hexenal/yomogi alcohol/tetradecane/ $\beta$-cyclocitral (6800). The significant differences encountered for the volatile composition of the $L$. aphaca and $L$. cicera volatiles point out the occurrence of different chemotypes. The fact that the compounds that creating the difference in the proposed chemotypes are the compounds that have different biosynthetic origins and it seems these compounds are restricted to different locations. However it should be noted that it seems plausible for certain case differences could be related to seasonal variations for certain compounds such as hexenal and $(Z)$-3-hexenal. These compounds seem to be produced at certain times in the season as could be clearly seen for L. gorgonei samples (6806 and 6809) which were collected from the same site with one week difference. The difference in collection periods or the altitude of the location could produce these changes. However the existence of compounds that have completely different biosynthetic origins such as yomogi alcohol, camphor, carvone and tetradecane specifically at samples from certain locations produce a strong clue that 


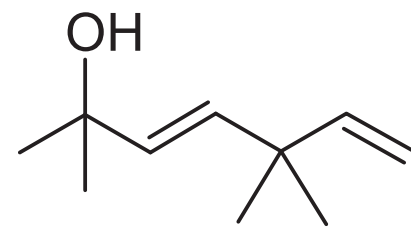

Fig. 2 Structure of yomogi alcohol.

the observed differences are not caused by the seasonal variations.

The essential oil composition of L. ochrus ${ }^{5)}$ and its volatile composition differed from one another however both oil and volatile contained high amount of alkanes. Volatile of $L$. ochrus contained mostly simple alkane alcohols, ketones and aldehydes where as essential oil of $L$. ochrus contained mostly alkanes, alkane aldehydes and acids with higher carbon number. The non-existence of the higher alkanes and diterpenes in volatile could be explained by their low volatility.

Unexpectedly volatile composition of the most of the Lathyrus species samples contained irregular monoterpene yomogi alcohol with high amounts. The irregular monoterpenes are formed by the isoprene units which are attached in non-head to tail fashion. They are reported to be restricted only for the species of the Asteraceae family ${ }^{20)}$. However there are some exceptions in which certain irregular monoterpenes were observed in other plant families including the occurrence of "Necrodols" in Lamiaceae and Convolvulaceae ${ }^{21,22)}$. The irregular monoterpene "yomogi alcohol" was first isolated from Japanese Artemisia feddei Lév. et Van. also known as Himeyomogi in Japan ${ }^{23)}$. After one year of its discovery, molecular structure of the yomogi alcohol was also confirmed by its synthesis $^{24)}$. Until now yomogi alcohol is reported from the members of the Asteraceae and Eryngium burgei of Apiaceae. Achillea, Artemisia, Anthemis, Bombycilaena, Eriocephalus, Otanthus and Tanacetum species were reported to contain high amounts of yomogi alcohol ${ }^{25-32}$. Structure of yomogi alcohol was given in Fig. 2. It is noteworthy that the volatiles we have investigated also contained compounds that were known only from synthetic sources. However the type of fragrance compounds which we have encountered in our studies including dihydromyrcenol, lilial, methyl dihydrojasmonate, hexylcinnamic aldehyde, 6-methyl- $\alpha$-ionone, 2-butoxyethanol were previously also reported from natural sources ${ }^{33-38)}$.

\section{Conclusion}

In conclusion, the volatile composition of seven Lathyrus species including $L$. aphaca, $L$. blepharicarpos var. cyprius, L. cicera, L. gorgonei, L. ochrus, L. sativus and L. saxatilis are reported for the first time. Three potential chemotypes of the L. aphaca and three potential chemotypes of the $L$. cicera species were observed with significant chemical differences. These potential chemotypes requires verification by employing DNA comparison studies. Additionally, it is worthy to note that Lathyrus species are highly suspected to display a seasonal variation in the quantity of the major volatile components including yomogi alcohol, camphor, $(Z)$-3-hexenal and hexenal. The seasonal variation study in this investigation was very limited therefore there is also a need for a detailed seasonal variation study of Lathyrus species. All of the investigated Lathyrus volatiles except for L. gorgonei contained an unknown substance $\left(\mathrm{M}^{+} 156\right)$ which could be a new oxygenated monoterpene. Most of the investigated Lathyrus species including L. aphaca, L. cicera, L. sativus, L. gorgonei, $L$. blepharicarpos var. cyprius contained the acyclic irregular monoterpene yomogi alcohol as the major component. Additionally, other irregular monoterpenes santolinatriene and artemisia alcohol were also observed in some sample of L. cicera (6802), L. gorgonei $(6809,6806)$ and $L$. aphaca (6810). Only L. ochrus, L. saxatilis and two proposed chemotypes of $L$ aphaca $(6795,6814)$ did not contain the yomogi alcohol or other irregular monoterpenes. Previously, only in Asteraceae species and in one species of Apiaceae this irregular monoterpene was reported as mentioned above. Our results indicate that the irregular monoterpenes are not restricted only to the members of the Asteraceae. Until now there has been limited information on the volatile secondary metabolite composition of Lathyrus species therefore we believe this study will stimulate future research.

\section{Acknowledgements}

This research was financially supported by The Scientific and Technological Research Council of Turkey (TUBITAKTOVAG 1110138).

\section{References}

1) Grela, E. R.; Studzinski, T.; Winiarska, A. Lathyrism in people and animals. Medycyna weterrynaryjna 56, 558-562 (2000).

2) Viney, D. E. An illustrated flora of North Cyprus. 2nd ed., Koeltz Publishing, Koenigstein, pp. 222-227 (1994).

3) Tajbakhsh, M.; Khalilzadeh, M. A.; Dabiri, H. A. Volatile constituents of Lathyrus rotundifolius Willd. and Trifolium mazanderanicum Rech. F. Two Papilionaceae herbs growing wild in Iran. J. Essent. Oil Res. 20, 119-121 (2008).

4) Iskender, N. Y.; Yayli, N.; Yasar, A.; Coskuncelebi, K.; 
Yayli, N. Volatile constituents of the flower, leaf and stem of Lathyrus vernus (L.) grown in Turkey. Asian J. Chem. 21, 6290-6294(2009).

5) Polatoğlu, K.; Arsal, S.; Demirci, B.; Can Başer, K. H. DPPH scavenging, PRAP activities and essential oil composition of edible Lathyrus ochrus L. (Cyprus Vetch, Luvana) from Cyprus. J. Oleo Sci. 64, 309-314 (2015).

6) Porter, A. E. A.; Griffiths, D. W.; Robertson, G. W.; Sexton, R. Floral volatiles of the sweet pea Lathyrus odoratus. Phytochemistry 51, 211-214(1999).

7) Akihisa, T.; Nishimura, Y.; Roy, K.; Ghosh, P.; Thakur, S.; Tamura, T. Sterols of three Leguminosae seeds: Occurrence of $24 \alpha$-ethyl- $5 \alpha$-cholest-9 (11) -en- $3 \beta$-ol and both C-24 epimers of 24 -ethylcholesta-5,25-dien-3 $\beta$-ol. Phytochemistry 30, 4029-4032 (1991).

8) Fuchs, A.; De Vries, F. W.; Landheer, C. A.; Van Veldhuizen, A. Odoratol and methylodoratol, two $\alpha$-hydroxydihydro-chalcone stress metabolites from Lathyrus odoratus. Phytochemistry 23, 2199-2201 (1984).

9) King, S. S.; Ahn, B. T.; Kim, J. S.; Bae, K. Lathyrus saponin, a new trisaccharide glycoside from Lathyrus japonicus. J. Nat. Prod. 61, 299-300 (1998).

10) Markham, K. R.; Hammett, K. R. W.; Ofman, D. J. Floral pigmentation in two yellow-flowered Lathyrus species and their hybrid. Phytochemistry 31, 549-554 (1992).

11) Markham, K. R.; Hammet, K. R. W. The basis of yellow coloration in Lathyrus aphaca flowers. Phytochemistry 37, 163-165 (1994).

12) Reynaud, J.; Ismaili, A.; Jay, M. Flavonoid glycosides of Lathyrus pratensis (Leguminosae). Phytochemistry 20, 2052-2053 (1981).

13) Robeson, D. J.; Ingham, J. L. New pterocarpan phytoalexins from Lathyrus nissolia. Phytochemistry 18, 1715-1717 (1979).

14) Udayama, M.; Ohkawa, M.; Yoshido, N.; Kinjo, J.; Nohara, T. Structures of three new oleanene glucuronides isolated from Lathyrus palustris var. pilosus and hepatoprotective activity. Chem. Pharm. Bull. 46, 1412-1415 (1998).

15) Ichimura, K.; Kohata, K.; Mukasa, Y.; Yamaguchi, Y.; Goto, R.; Suto, K. Identification of L-bornesitol and changes in its content during flower bud development in sweet pea (Lathyrus odoratus L.). Biosci. Biotech. Biochem. 63, 189-191 (1999).

16) Harrison, F. L.; Nunn, P. B.; Hill, R. R. Synthesis of $\alpha$ and $\beta$-N-Oxalyl-L- $\alpha, \beta$-diaminopropionic acids and their isolation from seeds of Lathyrus sativus. Phytochemistry 16, 1211-1215 (1977).

17) McLafferty, F. W.; Stauffer, D. B. The Wiley/NBS Registry of mass spectral data. John Wiley and Sons, New York (1989).
18) Koenig, W. A.; Joulain, D.; Hochmuth, D. H. Terpenoids and related constituents of essential oils. MassFinder 3. Hochmuth DH(ed). Convenient and rapid analysis of GC/MS, Hamburg, Germany (2004).

19) Joulain, D.; König, W. A. The atlas of spectra data of sesquiterpene hydrocarbons. EB-Verlag, Hamburg (1998).

20) Dewick, P. M. Medicinal Natural Products, A biosynthetic approach. $2^{\text {nd }}$ edition John Wiley and Sons. West Sussex, England, 186-187 (2001).

21) Kashima, Y.; Miyazawa, M. Chemical composition and aroma evaluation of essential oils from Evolvulus alsinoides L. Chem. Biodivers. 11, 396-407 (2014).

22) MI García-Vallejo, M. C.; Sanz, J.; Bernabe, M.; VelascoNegueruela, A. Necrodane (1, 2, 2, 3, 4-pentamethylcyclopentane) derivatives in Lavandula luisieri, new compounds to the plant kingdom. Phytochemistry 36, 43-45 (1994).

23) Hayashi, S.; Yano, K.; Matsuura, T. Yomogi alcohol a, a new monoterpene alcohol from Artemisia feddei lév. et van. Tetrahedron Lett. 9, 6241-6243(1968).

24) Willhalm, B.; Thomas, A. F. Synthesis and structure of yomogi alcohol, an alcohol related to artemisia alcohol. J. Chem. Soc. D. 1380a-1380a (1969).

25) Basile, A.; Rigano, D.; Sorbo, S.; Conte, B.; Rosselli, S.; Bruno, M.; Senatore, F. Antibacterial and antifungal activities of Otanthus maritimus (L.) Hoffmanns. \& Link essential oil from Sicily. Nat. Prod. Res. 27, 15481555 (2013).

26) El Bouzidi, L.; Abbad, A.; Hassani, L.; Fattarsi, K.; Leach, D.; Markouk, M.; Legendre, L.; Bekkouche, K. Essential oil composition and antimicrobial activity of wild and cultivated Moroccan Achillea ageratum L.: A rare and threatened medicinal species. Chem. Biodivers. 9, 598-605(2012).

27) Masoudi, S.; Rustaiyan, A.; Vahedi, M. Volatile oil constituents of different parts of Artemisia chamaemelifolia and the composition and antibacterial activity of the aerial parts of A. turcomanica from Iran. Nat. Prod. Commun. 7, 1519-1522(2012).

28) Mirahmadi, S. F.; Sefidkon, F.; Aalifar, M.; Akramian, M. Essential oil composition of Tanacetum polycephalum subsp. duderanum (Boiss) Podl., A Plant endemic from Iran. J. Essent. Oil Bear. Pl. 14, 742-745 (2011).

29) Mohammadhosseini, M.; Mahdavi, B.; Akhlaghi, H. Characterization and chemical composition of the volatile oils from aerial parts of Eryngium bungei Bioss. (Apiaceae) by using traditional hydrodistillation, microwave assisted hydrodistillation and head space solid phase microextraction methods prior to GC and GC/ MS analyses: A comparative approach. J. Essent. Oil Bear. Pl. 16, 613-623 (2013).

30) Pavlovic, M.; Lakusic, D.; Kovacevic, N.; Tzakou, O.; Couladis, M. "Comparative analysis of essential oils of 
six Anthemis taxa from Serbia and Montenegro. Chem. Biodivers. 7, 1231-1244(2010).

31) Sandasi, M.; Kamatou, G. P. P.; Viljoen, A. M. Chemotaxonomic evidence suggests that Eriocephalus tenuifolius is the source of Cape chamomile oil and not Eriocephalus punctulatus. Biochem. Syst. Ecol. 39, 328-338(2011).

32) Tsoukatou, M.; Vagias, C.; Harvala, C.; Roussis, V. Essential oil and headspace analysis of the maritime Bombycilaena erecta and Otanthus maritimus species growing wild in Greece. J. Essent. Oil Res. 12, 360-364 (2000).

33) Jirovetz, L.; Puschmann, C.; Stojanova, A.; Metodiev, S.; Buchbauer, G. Analysis of the essential oil volatiles of Douglas fir (Pseudotsuga menziesii) from Bulgaria. Flav. Fragr. J. 15, 434-437 (2000).

34) Radulović, N.; Blagojević, P.; Palić, R. Comparative study of the leaf volatiles of Arctostaphylos uva-ursi
(L.) Spreng. and Vaccinium vitis-idaea L. (Ericaceae). Molecules 15, 6168-6185(2010).

35) Rohloff, J.; Bones, A. M. Volatile profiling of Arabidopsis thaliana - Putative olfactory compounds in plant communication. Phytochemistry 66, 1941-1955 (2005).

36) Scrivanti, L. R.; Bernardello, G.; Anton, A. M. The foveola of Bothriochloa alta (Poaceae: Andropogoneae): Extrafloral nectary or secretory gland of essential oils? Flora 203, 55-59 (2008).

37) Sing, A. S. C.; Smadja, J.; Brevard, H.; Maignial, L.; Chaintreau, A.; Marion, J. P. Volatile constituents of faham (Jumellea fragrans (Thou.) Schltr.). J. Agric. Food Chem. 40, 642-646 (1992).

38) Vernin, G.; Vernin, E.; Vernin, C.; Metzger, J.; Soliman, A. Extraction and GC/MS-spectra data bank analysis of the aroma of Psidium guajava L. fruit from Egypt. Flav. Fragr. J. 6, 143-148(1991). 